\title{
Sciendo QUALITY CONTROL IN AEROSOL PRODUCTION
}

doi:10.2478/mape-2018-0012

Date of submission of the article to the Editor: 04/2018

Date of acceptance of the article by the Editor: 07/2018
MAPE 2018, volume 1, issue 1, pp. 85-91

\author{
Dr Anna Fitrzyk \\ JagoPro Sp. z 0.0., Poland \\ Katarzyna Niemiec \\ Silesian University of Technology, Poland
}

\begin{abstract}
Aerosol products are present in different industries including cosmetic, technical, household and many more. These products are subject to number of controls both at the pre-production, in-process and post-production stages. Controls at the pre-production stage relate to checking the conformity of individual components that make up the aerosol packaging, as well as raw materials that are used to create the formula. The checks carried out during the production process are mainly focused on the verification of parameters at particular stages of production. Whereas, post-production checks are related to the evaluation of the finished product. Due to the highest share of metal packaging in the aerosol products market, such products are the subject of this article.
\end{abstract}

Keywords: quality control, aerosol, AQL, metal container.

\section{LAW REQUIREMENTS AND OTHER}

The requirements for aerosol products and aerosol packaging are specified in binding legal regulations, subject standards as well as domestic and foreign standards. Legal requirements and technical requirements defined in standards, industry standards and technical specifications refer to the resistance parameters of the packaging, its dimensions and tolerances, required marking as well as product application parameters.

The document defining the requirements that must be met by the product to be placed on the European Union market is Directive 2001/95/EC of the European Parliament and of the Council of 3 December 2001 on general product safety (European Union, 2001). Notwithstanding that, the fundamental document relating to aerosol products is Council Directive of 20 May 1975 on the approximation of the laws of the Member States relating to aerosol dispensers (75/324/EEC) with amendments - called also ADD (European Union, 1975). This Directive specify, among others detailed requirements for ensuring safety, identification and labeling as well as conditions and procedures for testing aerosol products with metal containers with a volume of $50 \mathrm{ml}-1000 \mathrm{ml}$.

Due to the classification of aerosols as dangerous goods, they must also meet the requirements and regulations contained in the recommendations developed by the international committee of experts adopted by the United Nations Economic and Social Council on April 26, 1957. They concern: road transport (ADR), rail transport (RID), maritime transport (IMDG) and air transport (IATA-DGR) (Walecka, Wałachowski, 2012). These regulations define specific requirements for aerosol products regarding, i.e. carrying out a leak test of the packaging during production. Meeting these requirements is necessary to allow them to road transported.

Guidance on the requirements for aerosol containers and other parts of the aerosol packaging are regulated by the relevant legal requirements, industry standards, or FEA (European Aerosol Federation) standards and technical specifications. In order to standardize 
parameters for particular elements, specific standards agreed and accepted between suppliers and customers - usually filling companies - are used. On the other hand, the requirements for individual packaging elements and their dimensions have been specified in the relevant norms, standards and specifications depending on the packaging material used. In the case of metal containers, specific requirements regarding the packaging elements are specified in the standards presented in Table 1.

Table 1

Norms for aerosol packaging

\begin{tabular}{|l|l|}
\hline \multicolumn{1}{|c|}{ No } & \multicolumn{1}{c|}{ Title } \\
\hline EN ISO 90-3:2001 & $\begin{array}{l}\text { Light gauge metal containers - Definitions and determination of dimensions and } \\
\text { capacities - Part 3: Aerosol cans (ISO 90-3:2000) }\end{array}$ \\
\hline EN 14847:2005 & Aerosol containers - Tinplate containers - Dimensions of the 25,4 mm aperture \\
\hline EN 14848:2005 & $\begin{array}{l}\text { Aerosol containers - Metal containers with 25,4 mm aperture - Dimensions of valve } \\
\text { cups }\end{array}$ \\
\hline EN 14850:2005 & $\begin{array}{l}\text { Aerosol containers - Metal containers with 25,4 mm aperture - Measurement of contact } \\
\text { height }\end{array}$ \\
\hline EN 15006:2006 & Metal aerosol containers - Aluminium containers - Dimensions of the 25,4 mm aperture \\
\hline EN 15007:2006 & $\begin{array}{l}\text { Metal aerosol containers - Tinplate containers - Dimensions of two and three-piece } \\
\text { cans }\end{array}$ \\
\hline EN 15008:2006 & $\begin{array}{l}\text { Aerosol containers - Aluminium containers - Dimensions of one piece cans with 25,4 } \\
\text { mm aperture }\end{array}$ \\
\hline EN 15009:2006 & Aerosol containers. Compartmented aerosol containers \\
\hline EN 15010:2006 & $\begin{array}{l}\text { Aerosol containers - Aluminium containers - Tolerances of the fundamental dimensions } \\
\text { in connection with the clinch }\end{array}$ \\
\hline ISO 10154:1991 & $\begin{array}{l}\text { Light gauge metal containers - Three-piece necked-in tinplate aerosol cans - } \\
\text { Dimensions of the top end }\end{array}$ \\
\hline
\end{tabular}

In addition to the European standards listed in Table 1, industry standards, so-called FEA standards and FEA guides (Standards, 2018) are presented in table 2.

Additional requirements and expectations of packaging as well as of finished products containing packaging requirements are included in technical specifications and contractual arrangements. One such document is the Quality Agreement (QA), which includes quality assessment criteria and methods for quality control. Typically, the quality controls of the packaging or finished product are carried out using the statistical method according to the ISO 2859-1: 1999 - Sampling procedures for inspection by attributes - Part 1: Sampling schemes indexed by acceptance quality limit (AQL) for lot-by-lot inspection.

Table 2

FEA Standards and Guides

\begin{tabular}{|l|l|}
\hline \multicolumn{1}{|c|}{ No / Issue } & \multicolumn{1}{c|}{ Title } \\
\hline FEA 100 11/2013 & Standardisation - Basic terms, principles, procedure and layout \\
\hline FEA $101 /$ n/a & This standard is replaced by ISO 90/03 \\
\hline FEA 201 / n/a & This standard is replaced by EN14847 \\
\hline FEA 202 / n/a & This standard is replaced by EN14848 \\
\hline FEA 203 / n/a & This standard is replaced by EN15006 \\
\hline FEA 204 / n/a & This standard is replaced by EN15010 \\
\hline FEA 206 / n/a & This standard is replaced by EN14854 \\
\hline FEA 210/n/a & This standard is replaced by EN14849 \\
\hline FEA 214 / n/a & This standard is replaced by EN15007 \\
\hline FEA 215 / 03/2008 & Aluminium aerosol containers - Dimensions of 20 mm opening in monobloc containers \\
\hline FEA 216/ 10/2015 & Metal aerosol containers - Dimensions of the bearing surfaces of clinching jaws \\
\hline FEA 219 / 09/2010 & Aluminium aerosol containers - Dimensions of monobloc containers with 20 mm opening \\
\hline FEA 220 / n/a & This standard is replaced by EN 15008 \\
\hline FEA 222 / 08/2014 & $\begin{array}{l}\text { Metal aerosol containers - Guideline for achieving optimum clinch conditions for } \\
\text { containers with 25.4 mm opening }\end{array}$ \\
\hline FEA 223 / 03/2008 & $\begin{array}{l}\text { Tinplate aerosol containers - Plastic cover caps for two and three piece necked-in } \\
\text { containers conforming with FEA 214 }\end{array}$ \\
\hline
\end{tabular}




\begin{tabular}{|c|c|}
\hline FEA 224 / n/a & This standard is replaced by EN 15009 \\
\hline FEA 225 / 01/2015 & Aluminium aerosol containers - Dimensions of rimmed aluminium aerosol containers \\
\hline FEA 226 / 08/2014 & $\begin{array}{l}\text { Plastic aerosol containers - Guideline for achieving optimum external crimp conditions for } \\
\text { containers with } 25.4 \mathrm{~mm} \text { opening }\end{array}$ \\
\hline FEA $401 / \mathrm{n} / \mathrm{a}$ & This standard is replaced by EN 14850 \\
\hline FEA 405 / 03/2008 & Aerosol containers - Definition and method for measuring parallelism \\
\hline FEA $406 / 03 / 2008$ & Aerosol containers - Definition and method for measuring the planeness of the bead \\
\hline FEA $421 / 03 / 2008$ & $\begin{array}{l}\text { Aerosol containers with } 25.4 \mathrm{~mm} \text { opening - Definition and measurement of cover seat } \\
\text { height }\end{array}$ \\
\hline FEA 422 / 03/2008 & Filled aerosol packs - Standard fill level \\
\hline FEA 602 / 05/2014 & $\begin{array}{l}\text { Filled aerosol packs - Rapid test of the tightness of valve mechanisms and their } \\
\text { attachment to containers with } 25.4 \mathrm{~mm} \text { opening }\end{array}$ \\
\hline FEA 603 / 06/2017 & $\begin{array}{l}\text { Filled aerosol packs - Guidelines to test long-term preservation and to measure the loss } \\
\text { of weight }\end{array}$ \\
\hline FEA 604 / 09/2007 & Filled aerosol packs - Measurement of the internal pressure \\
\hline FEA 605 / 03/2009 & Filled aerosol packs - Measurement of the density of aerosol formulation \\
\hline FEA 606 / 09/2009 & Filled aerosol packs - Water bath testing - Verification of conformity with legislation \\
\hline FEA $608 / \mathrm{n} / \mathrm{a}$ & $\begin{array}{l}\text { this standard is replaced by point } 6.3 .3 \text { of the annex to the Aerosol Dispensers Directive } \\
75 / 324 / \text { EEC }\end{array}$ \\
\hline FEA $609 / \mathrm{n} / \mathrm{a}$ & $\begin{array}{l}\text { this standard is replaced by point } 6.3 .1 \text { of the annex to the Aerosol Dispensers Directive } \\
75 / 324 / E E C\end{array}$ \\
\hline FEA $610 / \mathrm{n} / \mathrm{a}$ & $\begin{array}{l}\text { this standard is replaced by point } 6.3 .2 \text { of the annex to the Aerosol Dispensers Directive } \\
75 / 324 / E E C\end{array}$ \\
\hline FEA $615 / 03 / 2008$ & Glass aerosol containers - Drop test \\
\hline FEA 621 / 03/2007 & $\begin{array}{l}\text { Aerosol containers - Measurement of internal pressure resistance of empty containers } \\
\text { without valves }\end{array}$ \\
\hline FEA 623 / 10/2014 & $\begin{array}{l}\text { Filled aerosol packs - Simplified method to measure mechanical resistance of metal and } \\
\text { plastic containers fitted with valve }\end{array}$ \\
\hline FEA $641 / 03 / 2007$ & Aerosol gaskets - Test for material selection \\
\hline FEA 642 / 03/2009 & Aerosol gaskets - Olfactive control test \\
\hline FEA 643 / 03/2008 & Filled aerosols packs - Measurement of discharge rate \\
\hline FEA 644 / 03/2009 & Filled aerosols packs - Evaluation of aerosol spray patterns \\
\hline FEA 646 / 03/2014 & Filled aerosol packs - Resistance to a top load force \\
\hline FEA 648 / 03/2014 & $\begin{array}{l}\text { Aerosol valve diptubes - Measurement of (a) diptube length, (b) diptube growth and (c) } \\
\text { diptube curvature }\end{array}$ \\
\hline FEA 650 / 01/2012 & $\begin{array}{l}\text { Filled aerosol packs - Measurement of the vacuum in a vacuum purged aerosol container } \\
\text { fitted with valve }\end{array}$ \\
\hline FEA $651 / 10 / 2015$ & Metal aerosol containers and valves - Assessment of internal coating coverage \\
\hline Guide / 01/2013 & FEA recommendation on small aerosols \\
\hline Guide / 09/2013 & Guide on Inhalation Safety Assessment for Spray Products \\
\hline Guide / 10/2017 & Guide on Hot Water Bath Testing and Its Alternatives - 3rd edition \\
\hline
\end{tabular}

Source: own elaboration based on FEA standards (Standards, 2018).

\section{QUALITY INSPECTION}

Inspection it is an activity such as measuring, examining, testing or gauging one or more characteristics of product or service, comparing the results with specified requirements in order to establish whether conformity is achieved for characteristic International Organisation for Standardisation, 1999).

During the AQL check, the assessment criteria are usually divided into three categories, in which there are descriptions of potential defects. The defect is understood as "non-fulfilment of an intended usage requirements" (International Organisation for Standardisation, 1999).These defect categories are: critical, major (essential) and minor (non-essential) and they are also assigned to levels of acceptable quality, according to which the acceptable number of defects for each category is determined.

In the case of critical defects there are requirements to meet critical parameters, i.e. quality characteristics, for which the determined requirements must be met. Failure to meet the above requirements may result, for example, in the lack of possibility to fulfill the product's functional functions, losses in the manufacturing process, risk to the natural environment and risk to the health or life of the user. 
Major features are the properties of the product's quality structure that directly affect the usability function and other user requirements. These characteristics must be included in the fixed quality requirements, and the control should be carried out in accordance with the recommendations of quality standards. Failure to meet these requirements may result in significant (major) defects that could damage the product or reduce its suitability for use as intended.

Whereas minor defects are those that do not cause limitations in the possibility of using the product as intended, but they are just a deviation from the set requirements and refer to nonessential, very often aesthetical features. All those characteristics require control during income of the products. The results of these control determine the acceptance or rejection of the delivery (Duda, 1994).

\subsection{Quality control of deliveries}

Raw material inspection

Each raw material which is a part of formula is controlled in accordance to the internal requirements and procedures. An employee equipped with appropriate protective clothing and appropriate equipment takes a sample from each batch and each delivery of incoming raw material. The sample must be taken in such a way as to prevent contamination of the raw material, and the raw material after collection is properly secured and marked with the label. The parameters controlled during income of the chemical raw materials are for example: appearance, color, density, $\mathrm{pH}$. In those ingredients that perform certain functions in the formula also the content of active substances or other specific properties are controlled. When all the parameters meet the specifications, the raw material is released for further production proceedings. In case of some parameters that are not possible to be tested in place, just the result from the certificate is compared with requirements.

\section{Packaging inspection}

Based on the FEA Standards as well as European Norms and legal requirements, Anna Fitrzyk has presented critical parameters of packaging elements of the aerosol products (Fitrzyk, 2016). In the case of steel containers, the critical parameters in terms of safety and quality of aerosol packaging are: contact height, outer and inner diameter of the opening, container end height and diameter at the end. These dimensions are considered critical due to the closure efficiency. In the case of protection with a cap or hood, the critical parameters should include the height and diameter of the necking and the outside diameter on the lid. In addition, parameters such as: total capacity, total height, external diameter of the side surface and the height of the overlap have been determined.

In case of aerosol containers made of aluminum, the critical parameters are: contact height, outside and inside diameter of the opening, parallelism, coaxiality and height of the container. These dimensions are considered critical due to the closure efficiency. In addition, parameters such as the total capacity and the height of the cap have been specified (Mumford, Dixon, 1966 and Sciarra, 1973).

Critical parameters in relation to valves used in aerosol packaging relate to: the diameter of the side of the seat, the outside diameter, the wall thickness of the plate, the height of the flange and the height of the valve.

On the basis of FEA industry standards (Standards, 2018) also crimping parameters are specified. Those parameters are critical for the tightness of the aerosol packaging, as crimping creates the connection of the valve with the container and it has a direct impact on its tightness and product safety. The container and valve parameters that are important in achieving the correct crimping for metal containers with an opening $25.4 \mathrm{~mm}$ are: contact height, wall thickness of the valve plate, thickness of the gasket after crimping.

FEA standards distinguish also critical parameters among the parameters affecting the proper selection of the caps, applicators and spraycaps and their compatibility with the filled container. 
They are outer diameter of the container, container end height, end diameter, container end height and the height of the cap fitting (covered surface). However, for the cap and applicator or spraycap, the following critical parameters should be indicated: the height of the cap, the diameter between the tabs and the supporting rim, the distance between the supporting rim and the edge and the maximum outside diameter. Failure to comply with the dimensions may result in the situation that the closure do not remain on the container or the difficulties in its removal and reinstallation may occur.

Based on the analysis of the requirements concerning the test methods for the parameters of aerosol packaging elements, which can be found in the FEA standards, it is necessary to indicate additional critical parameters concerning the diptube length and the diptube curvature, the continuity of the coating protecting the containers and valves and the resistance of the packaging to pressure. The FEA industry standards also define the methodology for testing critical parameters such as: deformation and burst resistance as well as leak tightness.

\subsection{In-process control (IPC)}

The person responsible for marketing the aerosol device should ensure that the container does not show visible and permanent deformations or leaks using appropriate test methods (European Union, 1975). The most popular method confirming tightness and resistance of the container in the finished product is the method of bath test in a water bath. Each product is immersed in a hot water bath, where the temperature and immersion time should allow the pressure in the aerosol product to be achieved as exerted by the contents of the container at a uniform temperature of $50^{\circ} \mathrm{C}$.

In-process control contains also weight verification of formula, gas and ready product on particular production steps. Also the crimping parameters should be controlled - it gives the certainty, that the valve is tightly fitted to the container. Another type of control which is required by EU regulation is gas pressure in $20^{\circ} \mathrm{C}$ and $50^{\circ} \mathrm{C}$. Allowed pressures are in detail presented in the Aerosol Directive and depend on the type of container, volume and percentage by weight of liquefied gas in the total mixture. The last type of IPC is appearance of the product, the evacuation level, and if necessary number of doses and dose volume. All control steps are presented on Figure1. 


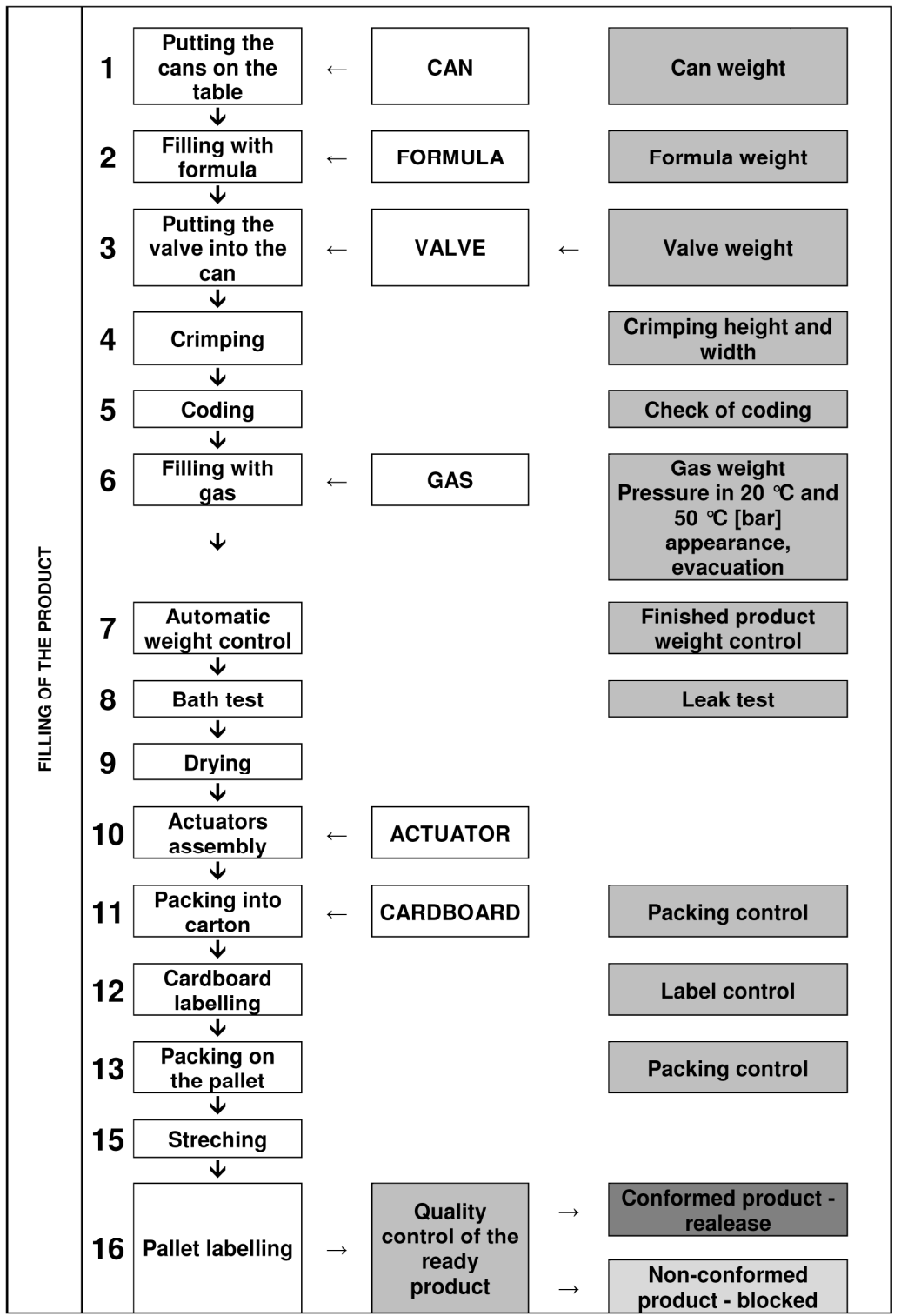

Fig. 1. Classic aerosols - filling process flowchart with control points

\subsection{Ready product control}

According to ADD an aerosol device should be equipped with a valve that allows tight sealing under normal conditions of storage or transport and should be secured, in particular with a protective cap against unintentional opening or damage. This product should be made in such a way that it is not possible to deteriorate its mechanical resistance due to the content of this product, even during prolonged storage.

Ready product controls are usually carried out in accordance with the AQL standard according to pre-defined criteria. Examples of the criteria for ready products are as follow:

- Critical defects: missing, wrong or illegible batch number and expiration date, lack of packaging element (cap, actuator), damage of packaging elements which cause leakage of product or ability to harm, type of packaging elements incompatible with approved one, incompatible appearance, $\mathrm{pH}$, mechanical and chemical contamination (heavy metals), microbiology, incompatible formula.

- Major defects: cap not perfectly fitted on the container, bigger visible dents on front of the container. 
- Minor defects (unimportantly reduce the aesthetic advantages of ready product): small dents on the product, scratches on the containers, wrongly placed label, small deviations in lithography colors.

\section{CONCLUSION}

The aerosol producers are very limited to the many legal requirements as well as standards, guidelines and arrangements with the clients. This is why, the quality control during aerosol filling process is very expanded. Beginning from the incoming control, where it is very important to check, whether all packaging components fulfill the requirements, thorough in-process control which guarantee that the ready product not only meet technical specifications, customers' expectations, but first of all is safe for the end user. The number of samples tested during all the production process, as well as number of quality controllers involved in the process always need to be properly analysed. The customer usually expects optimal quality at an economically justifiable cost. This is why effective quality management system, including quality control, is the basis in order to achieve this goal.

\section{SOURCE OF FINANCING}

Paid from the funds of the Ministry of Science and Higher Education under contract No. 12 / DW / 2017/01/1 of 07/11/2017 in the amount of PLN 4433520.00.

\section{REFERENCES}

European Union, (1975). Council Directive of the European Union of 20 May 1975 on the approximation of the laws of the Member States relating to aerosol dispensers. Brussel.

European Union, (2001). Directive 2001/95/EC of the European Parliament and of the Council of 3 December 2001 on general product safety. Brussel.

Fitrzyk, A. (2016). Determinanty jakości opakowań aerozolowych w branży kosmetycznej. PhD. Cracow: University of Economics.

International Organization for Standardization, (1999). ISO 2859-1: 1999 - Sampling procedures for inspection by attributes - Part 1: Sampling schemes indexed by acceptance quality limit (AQL) for lot-by-lot inspection. Geneva.

Mumford, R.M., Dixon, K. (1966). Laboratory Techniques and Quality Control. In: A. Herzka, ed., International encyclopedia of pressurized packaging (aerosols). New York: Pergamon Press, pp. $231-262$.

Niemiec, K. Fitrzyk, A., Grabowik, C., (2018). Technological solutions and innovations within aerosol packaging. In: ModTech International Conference. Romania.

Sciarra, J.J., (1973). Quality Control for Pharmaceutical and Cosmetic Aerosol Products. In: M.S.Cooper, ed., Quality control in the Pharmaceutical Industry, 2, pp. $1-54$.

Słownik pojęć towaroznawczych, (1994). In: I. Duda, ed., Cracow: Wydawnictwo Akademii Ekonomicznej w Krakowie.

Standards [online] FEA Standards Available at: http://www.aerosol.org/ publicationsnews/publications/standards/ [Accessed 23 Apr. 2018].

Walecka, E., Wałachowski, L. (2012). Opakowania do produktów niebezpiecznych - wymagania. In: W. Wasiak, ed., Przemysł opakowań w Polsce. Warszawa: Polska Izba Opakowań. 